\title{
High Purity Germanium, a Review on Principle Theories and Technical Production Methodologies
}

\author{
Danilo C. Curtolo, Semiramis Friedrich*, Bernd Friedrich \\ IME Institute of Process Metallurgy and Metal Recycling, RWTH Aachen University, Aachen, Germany \\ Email: *SFriedrich@ime-aachen.de
}

How to cite this paper: Curtolo, D.C., Friedrich, S. and Friedrich, B. (2017) High Purity Germanium, a Review on Principle Theories and Technical Production Methodologies. Journal of Crystallization Process and Technology, 7, 65-84.

https://doi.org/10.4236/jcpt.2017.74005

Received: June 11, 2017

Accepted: August 19, 2017

Published: August 22, 2017

Copyright $\odot 2017$ by authors and Scientific Research Publishing Inc. This work is licensed under the Creative Commons Attribution International License (CC BY 4.0).

http://creativecommons.org/licenses/by/4.0/

c) (i) Open Access

\begin{abstract}
Since the early 1950's the use of Germanium has been continuously growing as new applications are being developed. Its first commercial usage as the main material, from which the semiconductors were made, was later replaced by Silicon. The applications were then shifted to a key component in fiber optics, infrared night vision devices and space solar cells, as well as a polymerization catalyst for polyethylene terephthalate (PET). With the advance development in new technologies, the attentions have been brought back to Germanium due to its excellent semiconductor properties. New applications on the field of high efficiency solar cells, SiGe based chips, LED technologies, etc., are being developed and show a great potential. According to DERA (Deutsche Rohstoffagentur/German Mineral Resources Agency), the demand for Ge will grow considerably by 2030, pushed mostly by the increase in the fiber optics market and advanced materials sector [1]. Therefore, this paper focuses on an overview of the production chain of Germanium, especially from its concentrate up to the single crystal growth of its valuable ultra-pure metallic form to be used in high technological applications.
\end{abstract}

\section{Keywords}

Germanium, Fractional Crystallization, Crystallization, Refining, High Purity, Zone Melting, Czochralski

\section{Primary and Recycling Sources of Germanium, Worldwide Production and Prices}

Germanium $(\mathrm{Ge})$ is a dispersed element and has been estimated at $6.7 \mathrm{ppm}$ in the earth's crust [2]. Only found as trace amounts within many common metal- 
lic ore minerals, Germanium constitutes an uncommon element in earth and doesn't exist as native metal. In the few minerals in which $\mathrm{Ge}$ is the essential component, its amount is rarely feasible commercially. Principal minerals associations with Germanium are Arsenic, Gallium, Silicon, Tin, Zinc, and other elements [3]. The industrial production of Germanium nowadays comes from two main sources: zinc ores processing and coal fly-ashes. While most of Germanium produced is a by-product of zinc processing, some Germanium is extracted from the fly ash at coal-burning power plants [3]. The contribution of coal as a source in the overall supply of Germanium worldwide can be estimated in the range between $20 \%$ and $30 \%$ [4].

Within all producers, China remains the main supplier of Germanium, spread through several companies. However a company located in Canada is by far the biggest world producer, contributing to about $25 \%$ of the worldwide market supply of Germanium from its trail smelter and refinery plant in British Columbia [4]. Additionally, as important contributors in world's Germanium supply, Belgium, Russia and United States can be mentioned [5]. The following Figure 1 shows the main Germanium suppliers worldwide and their production in 2016 according to the USGS 2017 report [6].

Germanium has been always considered as a strategic metal for most governmental agencies and its supply and prices are often controlled in the form of stockpiles. Worldwide supply of Germanium ranges around 100 tons per year, with around $60 \%$ coming from zinc refining sources, and the rest mostly originated from fly-ash processing. The Figure 2 illustrates that despite of the prices fluctuation of Germanium metal, its primary production is constantly increasing, reaching 140 tons in 2008 and 160 ton in 2015 [5] [8].

Germanium producers are always focusing on the development of recycling processes to recover Ge from its own internal scrap and from end-of-life products. Recycled Germanium sources are mainly end-of-life as well as broken

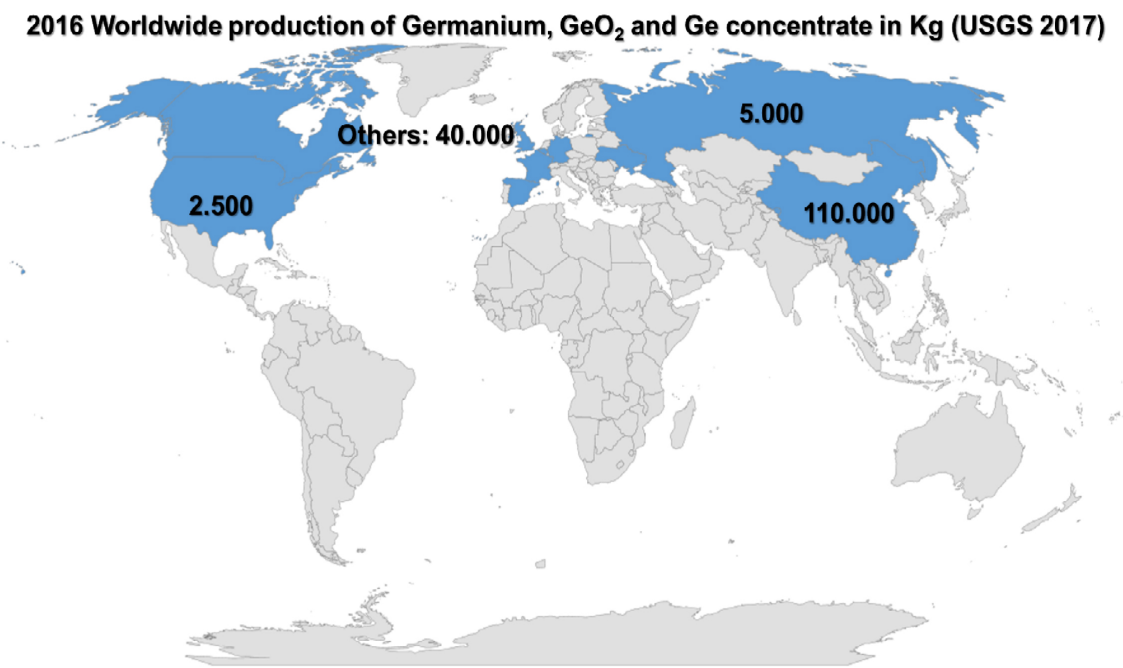

Figure 1. Production of germanium worldwide in 2016 according to USGS 2017 report [6] [7] adapted. 


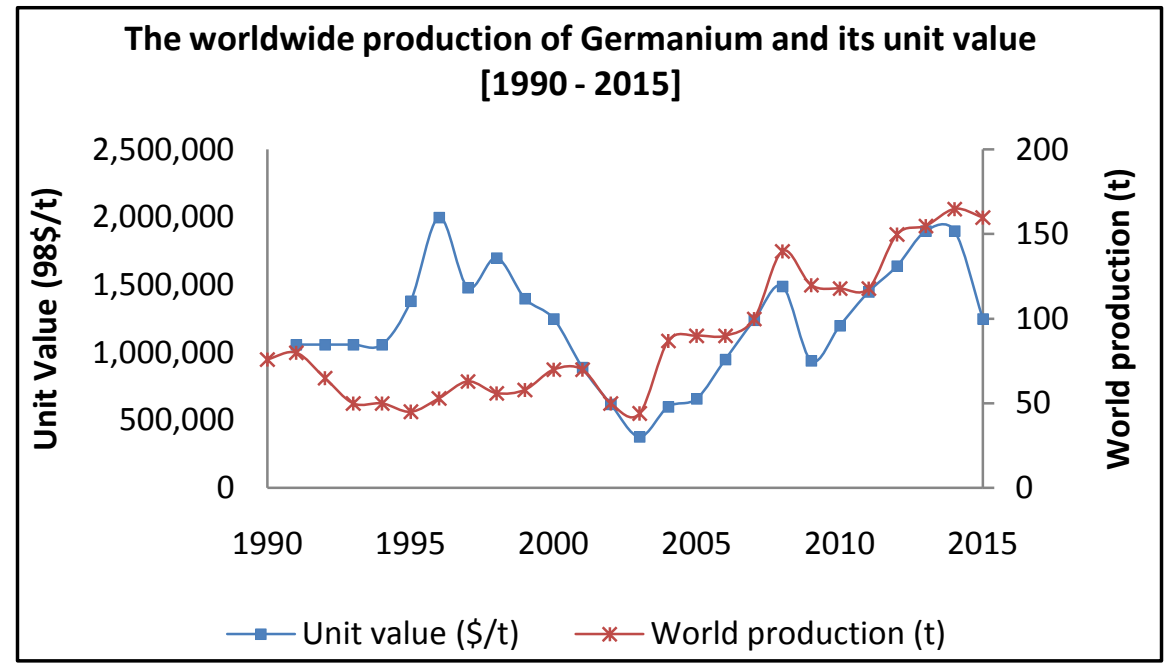

Figure 2. The worldwide production of germanium and its unit value, based on $[8]^{\star}\left({ }^{\star}\right.$ The consumer price index conversion factor, which is used to adjust the unit value in current US dollars to the unit value in constant 1998 US dollars).

Germanium lenses, semiconductor solar cells trimmings or optical fiber wastes. Furthermore, some Germanium contained products can be re-used within the manufacturing process as in the case of PET additives used in the plastic industry [3].

Although the contribution of internal scrap recycling is sometimes greater than $50 \%$ of total secondary sources, for post-consumer scrap (i.e. end-of-life products) this value is much smaller. It varies according to Germanium market prices and is controlled due to the complexity and costs of the recycling processes [3] [4] [9]. In spite of its constant efforts towards recycling, the amount of Germanium recycled from post-consumer scrap is not a significant contributor to world supply of Germanium [5].

\section{Main applications of Germanium}

Germanium applications rely on its intrinsic material properties: It is a semiconductor if it is in a pure metallic form and is able to perform at high frequencies and low operating voltages. Additionally, in crystal or glass form it is transparent to most of infrared light spectrum. It has also exceptional glass properties such as high refractive index and low chromatic dispersion. Another property of Germanium in its oxide form is to catalyze the polymerization process without giving undesirable color to the plastic products [9].

Therefore, the application of Germanium can be divided into five main categories, including polymerization catalysts, fiber-optic systems, infrared optics, electronics \& solar applications and other minor uses (e.g. metallurgy, phosphors and chemotherapy) [6]. The information about its distribution varies across the years. According to Melcher, et al. [1], the distribution of the main end-uses of Germanium worldwide during 2010 can be observed as in the Figure 3. 


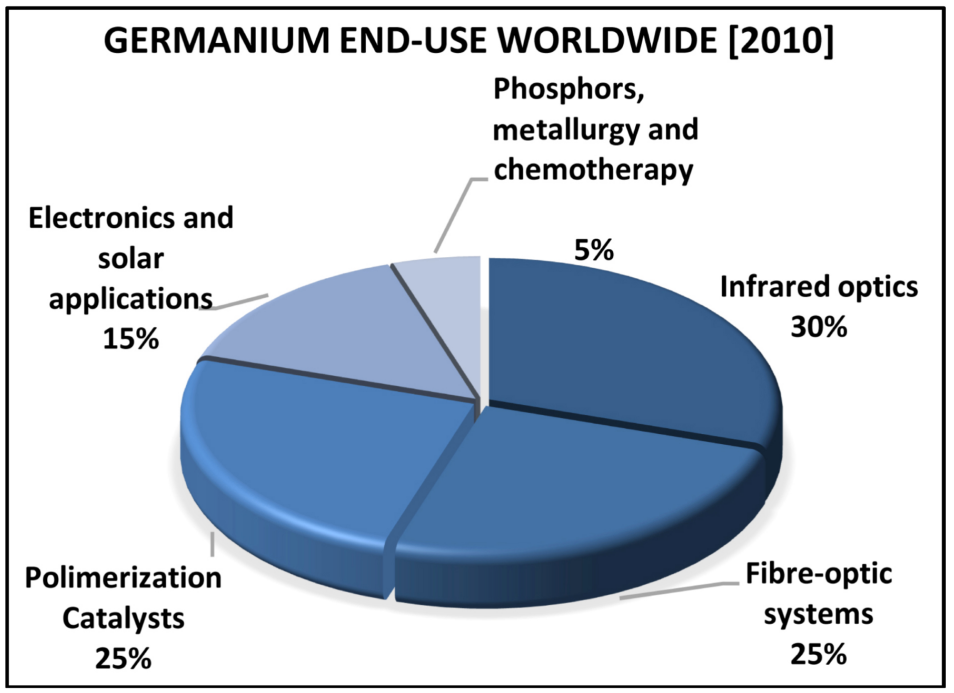

Figure 3. Worldwide end-use of germanium in 2010 [1].

Within its main applications, it's possible to separate three distinguished products in the production chain of Germanium: Germanium tetrachloride $\left(\mathrm{GeCl}_{4}\right)$, Germanium dioxide $\left(\mathrm{GeO}_{2}\right)$ and metallic Germanium. The pure Germanium tetrachloride finds its main application in the fiber-optic industry, where it is used as a dopant to the core of optical fibers [6]. The Germanium dioxide is used mainly as catalysts in the PET polymerization process-mostly in Japan and in the Infrared optic industry as an additive for glass. Although the PET industry is constant focusing its research towards finding an alternative for the expensive $\mathrm{GeO}_{2}$ in the polymerization process by using for example Ti-based catalysts, the Infrared sectors are still highly dependent of $\mathrm{GeO}_{2}$ due to its intrinsic characteristic as transparent to infrared radiation. The applications include a wide range from microscope objective lenses to night vision devices, finding its way deeper into military use, leading its definition as a strategic metal [10].

Being the first commercial use of Germanium and one of its most important applications in industry, the ultra-pure metallic form of Germanium is widely used due to its inherent semiconductor behavior [6] [9]. When doped with minor amounts of As, Sb, Ga, In, P and other elements, it is employed in many highfrequency and high-power electronics applications, as well as in space solar cells [11] [12].

Its utilization as semiconductor though represents the most important industrial uses of Germanium and has also the biggest future growth potential, especially on thin-film technologies for SiGe chips, Ge-based semiconductors and many other electronic applications. Many efforts are being made to replace GaAs by $\mathrm{SiGe}$ in wireless telecommunication devices, opening an important market to benefit from Germanium products. Additionally, Ge-based LED, Ge substrates as a replacement for Si on miniaturized chips, and many other implementations are constantly being investigated and developed in the electronic industry to explore the future potential of Germanium [4] [13]. 
Finally, Germanium can also be used as alloying element in metallurgical industries or in chemotherapy, as several organometallic compounds of Germanium are of interest in medicine due to its toxicity to certain microorganisms [10].

\section{Production of Ultra-Pure Germanium from Its Concentrate}

As described previously, Germanium appears as minor amounts in different minerals, mainly zinc ores and coal. Therefore, its cycle begins firstly with the production of Germanium concentrate (Germanium sulfide or oxide), followed by its chlorination and subsequent distillation/purification, producing ultra-pure Germanium tetrachloride as end product, then Germanium dioxide and subsequently the reduced metallic form. The latter will be further purified depending on its endapplication as well as purity requirements. In the Figure 4 an overview of the production steps of Germanium from mineral concentrate to crystal growth has been shown.

Germanium end concentrate, obtained from either zinc ore or coal fly-ashes and consisting between $0.5 \%-6 \%$ Ge [4], can follow either a hydro- or a pyrometallurgical route. The hydrometallurgical route includes leaching using sulfuric
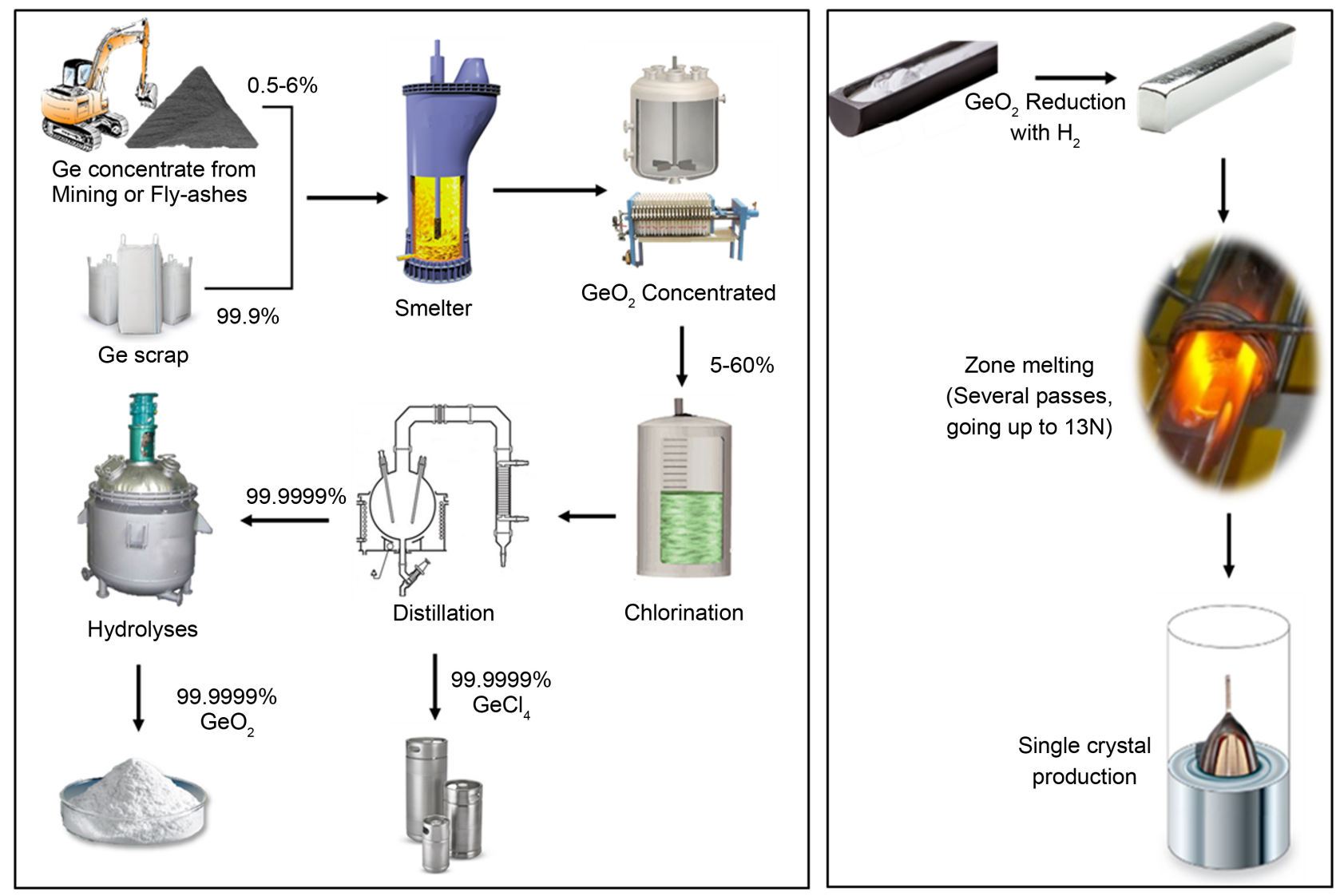

Figure 4. Example of production flow of germanium from concentrate to dioxide and tetrachloride via pyrometallurgical route (left) and from dioxide to ultra-pure metallic germanium (right), based on [1] [4] [14] [15] [16] [17]. 
acid and then an oxidization step of the precipitates back into $\mathrm{GeO}_{2}$. In pyrometallurgical way, mostly roasting or fuming process takes place, through which the $\mathrm{GeO}_{2}$ is volatized and collected in the fumes. In this process, a 10-factor increase in Germanium concentration can be obtained [4] [9] [18]. Recycling of Germanium scrap follows the same path as for the ore and fly-ashes concentrate, where Ge-dioxide is formed and the subsequent processes are performed [3] [4].

A chlorination process with Hydrochloric acid takes place on the concentrated Germanium dioxide collected from the smelter fumes according to the reaction showed in Equation (1). The product of this reaction is the crude Germanium tetrachloride $\left(\mathrm{GeCl}_{4}\right)$ accompanied by very low amounts of impurities, which are in the form of chloride as well. Since $\mathrm{GeCl}_{4}$ has a higher boiling point than most of those impurities, while distillation such impurities will be volatilized and the $\mathrm{GeCl}_{4}$ will be remained with a purity of up to $6 \mathrm{~N}$ [19]. The product of this step is then ready to be used by, e.g., fiber-optic industry [18].

$$
\mathrm{GeO}_{2}+4 \mathrm{HCl} \rightarrow \mathrm{GeCl}_{4}+2 \mathrm{H}_{2} \mathrm{O}
$$

For further processes, the ultra-pure $\mathrm{GeCl}_{4}$ is to be hydrolyzed with pure deionized water as shown in Equation (2). The result is pure Germanium dioxide that can be then reduced in hydrogen atmosphere (Equation (3)) into its first metallic form [3] [4] [18].

$$
\begin{gathered}
\mathrm{GeCl}_{4}+2 \mathrm{H}_{2} \mathrm{O} \rightarrow \mathrm{GeO}_{2}+4 \mathrm{HCl} \\
\mathrm{GeO}_{2}+2 \mathrm{H}_{2} \rightarrow \mathrm{Ge}+2 \mathrm{H}_{2} \mathrm{O}
\end{gathered}
$$

Controlling the temperature of Equation (3) is of great challenge in order to avoid the undesired back reaction between Germanium and vapor water that occurs at above $\sim 700^{\circ} \mathrm{C}$ and produces Germanium-Monooxide. Therefore, the reaction (3) should take place at temperatures between $650^{\circ} \mathrm{C}$ and $670^{\circ} \mathrm{C}$. When the reduction is accomplished, the temperature can be increased to around $1000^{\circ} \mathrm{C}$ so that the metallic $\mathrm{Ge}$ is melted and casted into the zone melting appropriate molds and sent to the further purification steps [19]. Later the ultra-pure material will be grown as a single crystal for specific applications. Both processes will be explained in the next chapters.

\subsection{Methodologies of Germanium Purification and Their Principles}

Mostly all of the existing methodologies to refine Germanium after $\mathrm{H}_{2}$-reduction step (see Chapter 3) are based on the general principle of fractional crystallization. This principle is based on the difference in the solubility of the impurities in the molten and solid phase of a metal. This relation is called distribution coefficient $(k)$. The " $k$ " coefficient defines the purification degree that can be theoretically achieved in a system. While at equilibrium, distribution coefficient can be taken from a binary phase diagram at a constant temperature, where it is the relationship of the concentration of the impurity element in the solid phase $\left(C_{S}\right)$ to its concentration on the molten phase $\left(C_{L}\right)$ of the base metal, represented in 
the Equation (4).

$$
k=\frac{C_{S}}{C_{L}}
$$

When $k$ is less than one, the solute tends to remain in the molten phase or in the last crystallized areas, e.g. between the dendritic arms upon crystallization. While for $k$ bigger than one, the impurities tend to remain in the solid during crystallization. Finally, when $\mathrm{k}$ is close to 1 , quite no purification can be achieved by fractional crystallization [20] [21] [22].

The distribution coefficient $\mathrm{k}$ is only valid under assumption of a homogeneous distribution of impurities in the liquid phase. A more realistic approach can be evaluated through the effective distribution coefficient $\left(k_{\text {eff }}\right)$, shown in Equation (5) and detailed described by Burton, Prim and Slichter in their article regarding the distribution coefficients of solute elements in Germanium [22] [23] [24].

$$
k_{\text {eff }}=\frac{k_{0}}{k_{0}+\left(1-k_{0}\right) \cdot \exp \left[-\frac{V \delta}{D}\right]}
$$

where $\delta$ is the thickness of the diffusion boundary layer, $k_{0}$ is the ratio $C_{\mathrm{s}} / C_{0}, D$ is the impurity diffusivity in the melt and $V$ is the solid growth rate.

When a maximum mixing of the removed solute into the melt occurs, the value of $K_{\text {eff }}$ becomes very close to that of $k$, showing the most optimum purification. In reality and while crystallization, the impurities enrich the melt ahead of the crystallization front, so that this region contains a higher amount of solute (see Figure 5).

The region in which the impurities are concentrated from the solid/liquid interface up to the distance where the solute concentration is approximate the same as the bulk concentration is called diffusion boundary layer, and its thickness

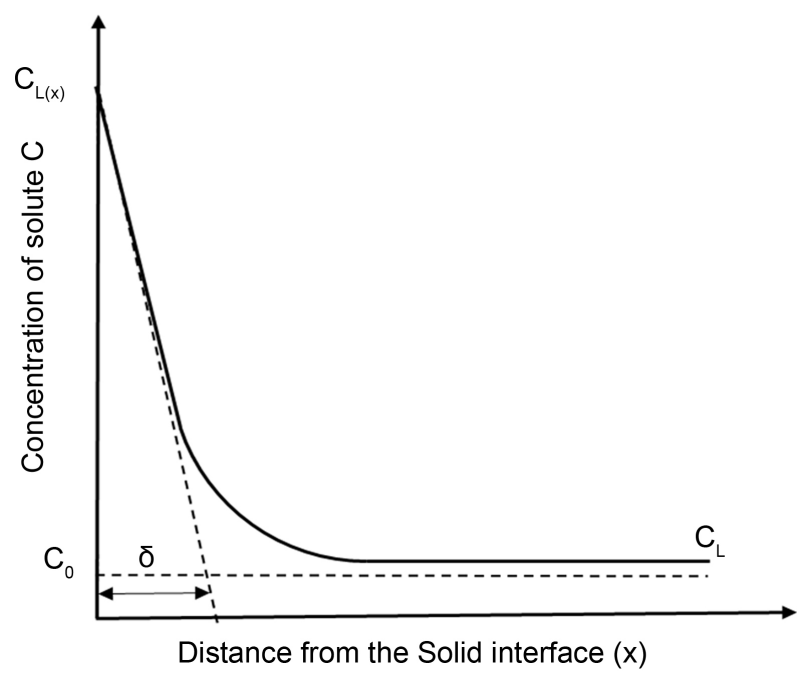

Figure 5. Change in solute concentration ahead the solidification front [25]. 
is represented by $\delta$. Within this film layer, impurity transport is assumed to occur only by diffusion. Mechanisms, while ahead of this layer the transport is done mainly by convection and other mixing mechanisms [26] [27] [28].

Despite being physically challenging to precisely measure the diffusion boundary layer thickness $(\delta)$, the value of $\delta / D$ has been already obtained experimentally by Burton, Prim and Slichter and the results of their investigation are shown as in Equation (6) under the so called BPS model [23] [24].

$$
\ln \left(\frac{1}{K_{\text {eff }}}-1\right)=\ln \left(\frac{1}{K_{0}}-1\right)-\frac{G \delta}{D} \quad \text { for } K_{0}<1
$$

By plotting the value of $\ln \left(1 / k_{\text {eff }}-1\right)$ against growth rate, with $K_{\text {eff }}$ being the ratio of impurity concentration on the crystallized material $\left(C_{s}\right)$ to the concentration of the impurity at the bulk metal $\left(C_{L}\right)$ and growth rate obtained for a constant mixing behavior at the growth interface, one could extract through a linear curve fitting the slope representing the value $-\delta / D$ [23] [29].

\subsection{Distribution Coefficient of Impurities in Germanium}

With some exceptions, most impurities in Germanium have their $\mathrm{k}$ value around $10^{-3}$ to $10^{-5}$, facilitating its removal by fractional crystallization. Some impurities however, have $k$ much bigger than one; such as B and Si. Additionally, impurities as $\mathrm{Al}, \mathrm{Ga}$, and $\mathrm{P}$ have their distribution coefficient around 0.1 , leading to their removal in a slower rate [30]. Table 1 contains the distribution coefficients of impurities in Germanium, showing significant deviations according to different authors.

\subsection{Ultra-Purification of Germanium}

To obtain the ultra-pure metallic form, the zone-refining technique has been

Table 1. Distribution coefficient of impurities in germanium based on a variety of references.

\begin{tabular}{|c|c|c|c|}
\hline Element & Range of $\mathrm{K}$ & Element & Range of $K$ \\
\hline $\mathrm{Li}[31]$ & 0.002 & $\mathrm{Tl}[20][31]$ & $(1.0-4.0) \times 10^{-5}$ \\
\hline $\mathrm{Cu}[31]$ & $1.5 \times 10^{-5}$ & Si [31] [33] [34] & $1.5-5.5$ \\
\hline $\mathrm{Ag}[31]$ & $4.0 \times 10^{-7}$ & $\mathrm{Pt}[32]$ & $5.0 \times 10^{-6}$ \\
\hline $\mathrm{Au}[31]$ & $1.3 \times 10^{-5}$ & Sn [20] [31] [33] & $0.019-0.02$ \\
\hline $\mathrm{Zn}[31]$ & $4.0 \times 10^{-4}$ & $\mathrm{~Pb}$ [31] [33] & $(1.0-1.7) \times 10^{-4}$ \\
\hline $\mathrm{Cd}[31]$ & $1.0 \times 10^{-5}$ & $\mathrm{P}[31]$ & 0.08 \\
\hline B [31] [33] & $6.0-17.0$ & As [20] [31] & $0.10-0.02$ \\
\hline $\mathrm{Al}[20][31][33][34]$ & $0.0073-0.20$ & $\mathrm{Sb}[20][31]$ & $0.0030-0.020$ \\
\hline $\mathrm{Ga}[20][31]$ & $0.02-0.087$ & $\mathrm{Bi}[20][31]$ & $4.5 \times 10^{-5}$ \\
\hline In [20] [31] & $0.0008-0.001$ & $\mathrm{O}[35]$ & $1.0-1.4$ \\
\hline
\end{tabular}


widely used in the process of Germanium purification. It's principle is to push the impurities to both ends of the sample-depending on how low or high the distribution coefficient of those impurities are-via unidirectional movement of one or several molten zones through a solid sample [21] [36]. As seen in the sketch of Figure 6, the heating (mostly inductive) coil(s) passes through the Germanium ingot, producing molten zone(s). This zone moves consequently while the coil travels along the ingot. The area staying behind the molten zone then solidifies. Most of the impurities will be concentrated in the moving molten zone and will remain at the end of the bar, which is later cut away. In a so called multi zone refining method, multiple zones at the same pass are applied to reduce the overall process time. Although such technique is widely available on the market for other metal systems, no publication was found about the application of this technique for Germanium purification.

Zone refining can be generally carried out through both horizontal as well as vertical systems. Surface tension is one of the most important thermo-physical properties, which influences the possibility of a vertical process by controlling the meniscus effect. However, referring to Germanium and Silicon, whose surface tension values are indeed different but not too much far from each other ( $\mathrm{Si}$ $783 \mathrm{E}-3 \mathrm{~N} / \mathrm{m}, \mathrm{Ge} 591 \mathrm{E}-3 \mathrm{~N} / \mathrm{m}$ ), there should be some other influencing parameters making Germanium inadequate for a vertical zone refining, while Silicon is quite common to be applied in a crucible-free vertical system. This parameter is density-also a physical property-that is more than double for Germanium and will generate an excess of pressure on the melt meniscus, causing it to collapse and the germanium to flow out of molten zone. Therefore and at least on earth, where a density/weight ratio is not negligible, Germanium cannot be refined in a vertical zone melting equipment [21] [36].

Zone refining is affected by a variety of process parameters, such as size of the zone length, number of passes, zone movement velocity, inclination angle, equilibrium distribution coefficient $(k)$, crucible design as well as atmosphere/vacuum levels; the most important of them as well as their impact on the process and product quality are described in the following. The achieved end purification through this method can be up to $13 \mathrm{~N}$, depending on the starting purity and among others, the below mentioned process parameters.

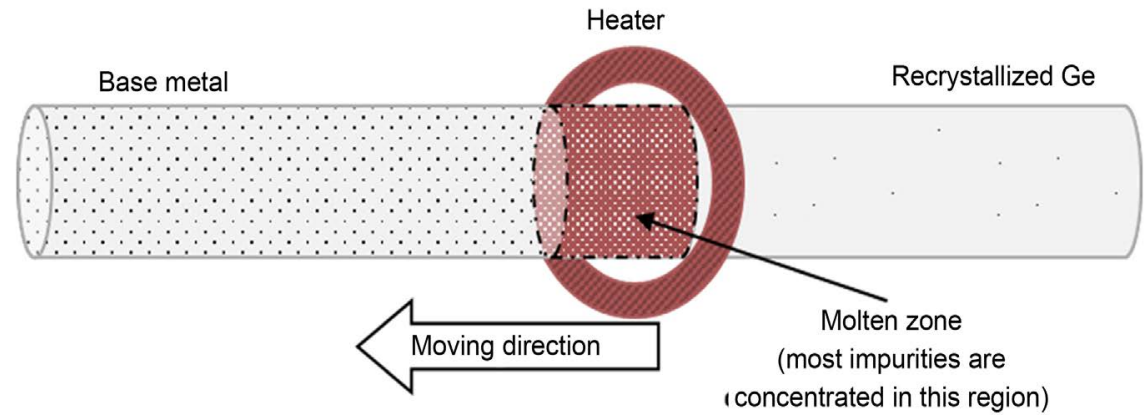

Figure 6. Schematic representation of the zone melting process with single heater. 
Zone length: Spim et al. [36] states that longer molten zones have more beneficial effect when performed at the earlier passes, while for the later passes the shorter molten zones showed the result more efficiently. This statement has been also confirmed by Rodway et al. [37] as they explain that a long molten zone could cause poor solute distribution. While using smaller zones requires a large number of passes to achieve the desired purification. According to the authors, when $k<1$, longer zones tends to induce a more rapidly initial purification, since as the molten zone passes through the sample, the rejected impurity is diluted into a large portion of molten material. On the other hand, a shorter zone favors a better ultimate distribution of impurities, especially for values of $\mathrm{k}$ close to unity. As most impurities in Germanium have their distribution coefficient either much smaller or much higher than unity, longer zone lengths might have an advantage on the purification of Germanium through zone melting due to a more efficient dilution of impurities into the molten zone, favoring a more rapidly purification. Shorter zones could be then used in the later passes to achieve a better ultimate purification. Haller et al. [30] for example, applied a $30 \mathrm{~mm}$ molten zone length in his work while investigating the parameters of zone refining in the production of ultra-high purity Germanium.

Number of passes: Many passes increase the purification effectiveness; though they have a great impact on the process time and costs as well [36] [37] [38]. Wang et al. [39] demonstrated that the effectiveness of a series of passes increases greatly the impurity segregation and final purification of Germanium.

Zone movement velocity: This process parameter directly controls the growth rate of the solid part of the material at the crystallization front interface and consequently plays a determinant role in the final achieved purification degree. Yang et al. found an optimum movement velocity of $1.16-1.33 \mathrm{~mm} / \mathrm{min}$ for Germanium purification for high-tech applications as radiation detector. While with minor deviation, similar conditions (i.e. $1.66 \mathrm{~mm} / \mathrm{min}$ ) were confirmed by Haller et al. [30] [40]. The value of molten zone movement velocity amounts rarely to above $2.0 \mathrm{~mm} / \mathrm{min}$, according to the most publications; otherwise in the case of too fast processes the purification yield would be significantly decreased. That is also valid for the "non-Germanium" systems such as tellurium, Selenium, cadmium or Silicon [38] [41] [42] [43]. For certain elements like Al, $\mathrm{Ga}$, and $\mathrm{P}$, with distribution coefficient closer to unity, a very difficult segregation of such impurities should be expected, since as shown by Wang et al. [39], the removal of such impurities would require extreme low values of growth rate, which is not viable practically.

Inclination Angle: After several passes, the molten zone movement tends to promote a mass transport due to the difference in densities from molten and solid material. This fact results in a higher mass concentration on one side of the bar, leading to have an unequal height along the bar. This effect can cause an uneven zone during the process or spill the melt over solid bar. As seen in Figure 7, a higher mass concentration will be developed opposite to the direction of the zone pass, if the metal expands while it is liquid. An opposite behavior will 


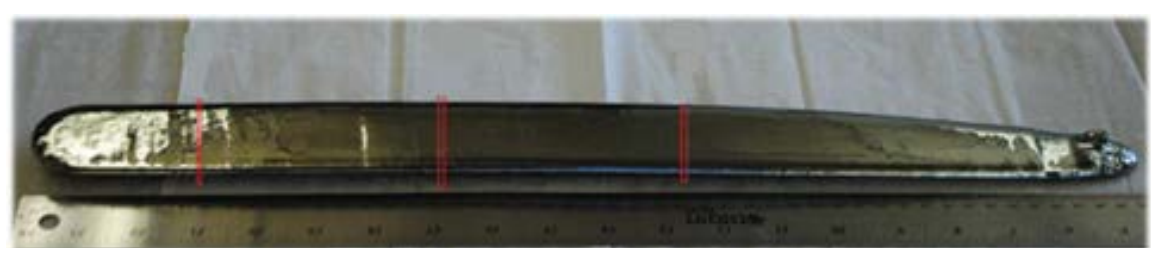

Figure 7. Effect of the mass transport into the bar as the molten zone moves across the bar for a system with a melt density higher than the solid, e.g., germanium [40].

occur if the melt has lower density than the solid (which is the case of Germanium). This inclination angle in the final ingot seems to be increased as the number of pass increases [21].

To compensate this effect, the crucible could be installed with a slight inclination by tilting to some degrees, depending on which metal system is being refined. This modification usually does not affect the final purification grade and has even a positive influence on the homogeneity of the bar [44]. The value of this angle is directly related to the molten zone size, length of the bar and the ratio of solid and liquid densities, and can be described by the Equation (7), as well as Figure 8, where, $\theta$ is the inclination angle, h the height of crucible, $\mathrm{L}$ molten zone length and $\alpha$ the density ratio between solid and molten phase. Additional effects like surface tension, wettability, stirring, etc. can have an influence on the value of the inclination angle too [45].

$$
\theta=\frac{l}{\tan (2 \cdot h(1-\alpha))}
$$

Distribution coefficient: As mentioned before, this factor $(K)$ will indicate the achievable impurity segregation level in the fractional crystallization process. The closer the $\mathrm{k}$ value (see Equation (4) from Chapter 3.1) is to unity, the more difficult is for the element to be separated from the base metal. Most of the impurities presented in Germanium have very low distribution coefficients $\left(10^{-3}\right.$ to $10^{-5}$ ), allowing to be removed via fractional crystallization [34] [39].

Crucible: Compatibility within metal and crucible has an essential role on the process design. When it comes to purification processes, the chemical stability between the two parts is essential to assure the most optimal results. Additional characteristics like compatibility with heating system (e.g. graphite in induction system), design of melt "chamber" to accommodate the expansion or contraction of metal and low wetting between substrate and base metal are some examples of desired properties from a crucible [34] [46].

Solidification of Germanium in Quartz crucibles during the zone refining process will most likely damage the crucible, since Germanium wets the quartz substrate. One solution described in details by Hubbard [34] and successfully applied by Yang [30], is the coating of ultra-high purity quartz with carbon, allowing then to achieve extreme high levels of Germanium purification.

Atmosphere: While most of the contamination originates from crucible, some impurities can also be induced from the process atmosphere [4]. Hubbard 


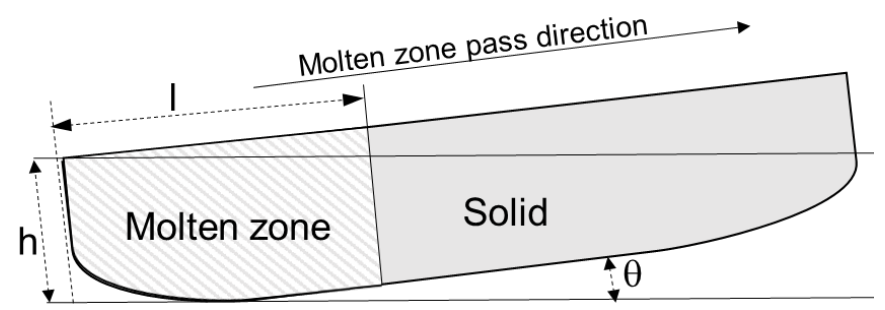

Figure 8. Angle applied in a system with solid density lower than liquid density (e.g. germanium) [45].

et al. successfully used a mixture of $90 \% \mathrm{~N}_{2}$ and $10 \% \mathrm{H}_{2}$ as reductive atmosphere while investigating the impurities behavior on zone refining of Germanium [30]. Also, good results could be delivered through applying of a vacuum level of $10^{-5}$ torr while producing detector-grade Germanium [40].

\subsection{Crystal Growth of Germanium}

In order for Germanium to be used in the electronics and semiconductors areas, not only its end-purity should be noted, but also its crystalline form in terms of crystal orientation, distribution of doping elements across the crystalline structure as well as the crystal defects such as vacancies, dislocations, etc. Among the methods of producing single crystalline Germanium, Vertical gradient freeze (VGF), Bridgman and Czochralski are the leading processes to produce Germanium single crystals from a specific crystalline-oriented seed. Although both VGF and Bridgman methods are used to produce single crystals of Ge for a variety of applications, Czochralski remains the most used process to obtain the highest performance single crystals, such as the ones used for large diameter radiation detectors and therefore this process will be focus below [47].

\section{Czochralski Process}

The Czochralski process is the most used method to obtain a single crystalline form from a melt, where a "seed crystal" with specified crystalline orientation is inserted in the melt surface and slowly pulled out while rotating around its vertical axis. That result into a uniform growth of this seed into the desired dimensions, as seen in Figure 9. While mostly used for the production of single crystalline Silicon for electronic and monocrystalline photovoltaic applications, Czochralski methodology is also widely applied for Germanium as well. In spite of not being commonly used as a refining method, some degree of purification can be though reached or even controlled in terms of elements' distribution along the ingot, e.g., dopants [3] [4] [48]. Therefore, although this is a very complex process, only a superficial approach will be done in terms of the process parameters concerning its influences on the impurities segregation behavior during crystallization, mainly regarding temperature, atmosphere and growth rate controlling.

Czochralski methodology is affected by a variety of process parameters too. They are including growth rate, rotation rate, temperature gradient as well as 


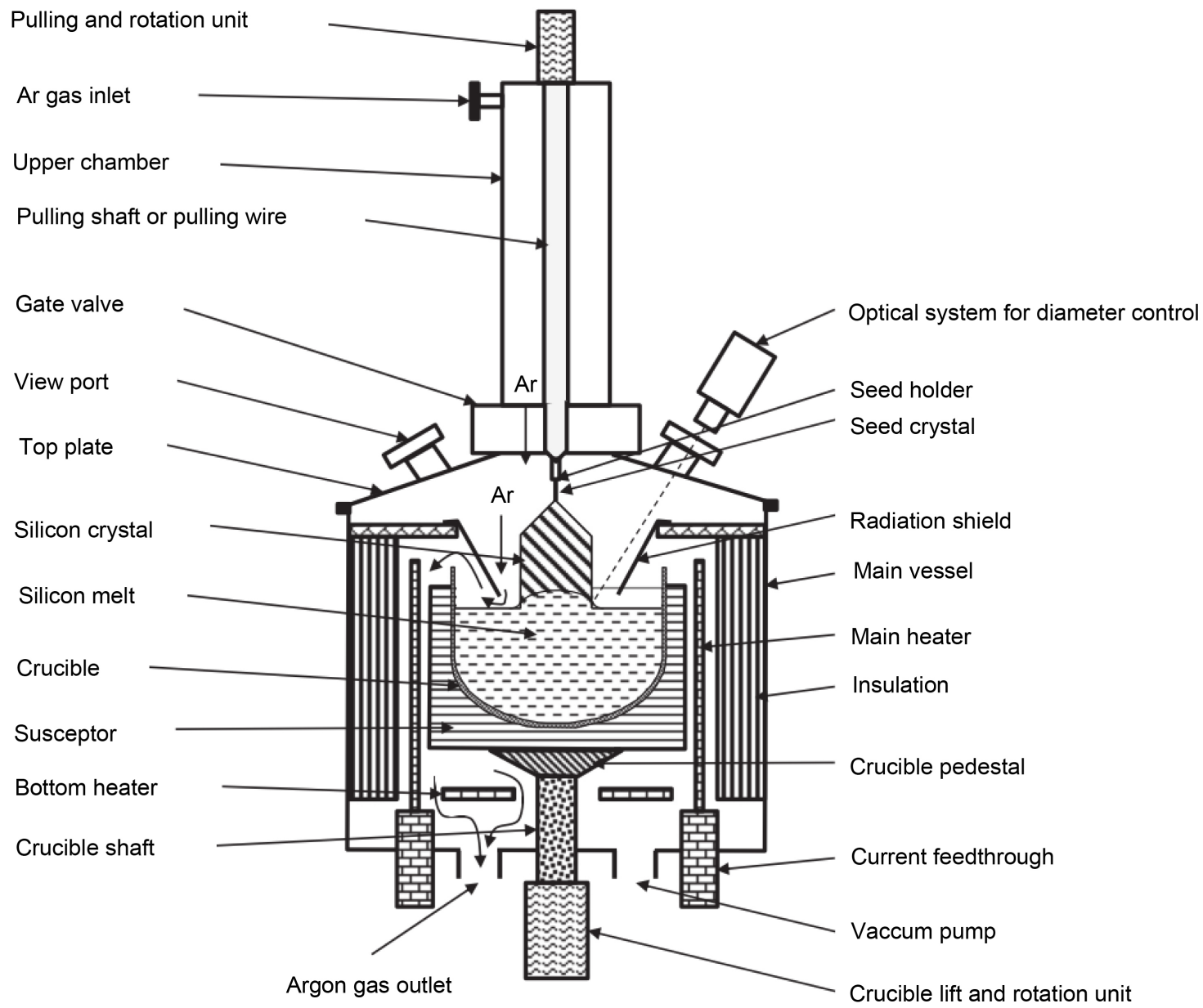

Figure 9. A general Czochralski setup [53].

atmosphere.

Growth rate control: The growth rate on the crystal pulling method is controlled by the supercooling at the solid/liquid growth interface as well as by the heat transfer from this interface into the crystal. The heat balance at the interface at one dimension $(x)$ can be formulated according to Equation (8):

$$
\lambda_{s} \cdot\left(\frac{\delta T}{\delta x}\right)_{S}=\lambda_{I} \cdot\left(\frac{\delta T}{\delta x}\right)_{I}+\rho \cdot V \cdot L
$$

where $\lambda_{s}$ and $\lambda_{l}$ are the thermal conductivity of solid and melt, $(\delta T / \delta x)$ the temperature gradient along the growth direction for the solid and the melt at the solid/liquid interface, $V$ the growth rate, $\rho$ the density and $L$ is the latent heat.

As shown in Equation (8), in order to induce the growth the temperature gradient in the solid must be higher than of the liquid. Additionally, the heat is removed from the system through the crystal and then to the subsequent cooler parts of the equipment (considering no natural heat losses from equipment, insulation, etc.), therefore one concludes that the growth rate $(V)$ is not only driven by the growth kinetics but also in a great extent by the heat transfer. Furthermore, with increasing crystal diameter, the growth rate decreases due to the 
less efficient cooling of the crystal [49].

At steady state of growing with constant crystal diameter, the growth rate can be described as the pulling rate. In literature, the pulling rates used for Germanium crystal growth varies greatly from $0.16-1.5 \mathrm{~mm} / \mathrm{min}$. This wide process interval is mainly due to the significant influences that other parameters have on the growth rate and to which diameter the crystal has been grown [35] [50] [51] [52].

Rotation rate: One approach to reduce the temperature gradient in the melt is to keep the heat flow from the melt to the interface as small as possible. This is mainly determined by the convective flows inside the melt and can be controlled by the rotation of crystal and crucible. The crystal rotation will promote a mass flow in the melt, resulting in a stable boundary layer in front of the solid-liquid interface, allowing a uniform segregation or incorporation of impurities (in case of dopants). Similar to the crystal rotation, the crucible rotation also promotes a mass flow at the crucible-liquid interface and its rotational is typically in the opposite direction as the crystal rotation. The control of the boundary layer by the rotation of both crystal and crucible and its subsequent benefits on stable growth is one of the reasons of the high success of the Czochralski method [49]. The values of rotation rate in Germanium Czochralski crystal growth also varies significantly in the literatures from $10-60 \mathrm{rpm}$ for the seed crystal rotation and 1 - $5 \mathrm{rpm}$ for crucible rotation [50] [51] [52].

Temperature and temperature gradient control: After being melted, the temperature needs to be stabilized and kept slightly (maybe about 1 - 3 degrees) above the liquidus point. The process and furnace temperature should be designed in such a way to keep the coldest region, where later the seed will be placed, at the center of the surface. Due to the very high convective flow in the melt, it is of great challenge to achieve the steady conditions. Nevertheless, the melt temperature should be kept as stable as possible during the growth process to avoid thermal stresses in the growing crystal [53]. Heat losses are kept as minimal as possible here through installation of heat shields and insulation materials [53]. Additionally, the transformation from melt to solid itself brings some latent heat into the system too, necessary to be taken into account [49].

A constitutional supercooling effect can be also generated due to the impurities segregation ahead of the crystallization front, since most impurities as well as all $\mathrm{n}$-type dopants in Germanium have its distribution coefficient smaller than unity. Under higher growth rates and lower temperature gradient, the temperature of the boundary layer could become lower than the equilibrium liquidus temperature. This supercooling effect will most likely induce growth instabilities, leading to high dislocation densities in the forming crystal [54].

Atmosphere influences on growth and crystal quality: Typically, an Argon atmosphere from 20 - 500 mbar is used as a carrying mechanism to remove the evaporated material from the melt surface. Also it promotes a slight cooling of the melt surface facilitating the crystal growth [49]. Some authors suggest dif- 
ferent approaches depending on the desired end-product quality. Yang et al. [55] found that the impurity concentration in the crystals grown under a hydrogen atmosphere has reached levels that fulfill the requirements of detector-grade crystals. While in the case of crystal grown under Argon atmosphere, the obtained resistivity distribution along axial direction was not uniform, Yang et al. indicate some influences from the Argon atmosphere (in combination with 1.5 $\mathrm{L} /$ min Hydrogen) on the product quality as well as on impurities and defects distribution. Despite the fact that the relative easier dissolution of hydrogen into molten Germanium lead to form divacancies $\left(\mathrm{V}_{2} \mathrm{H}\right)$, this effect will only be critical if upon crystallization the dislocation density increases to a number higher than $10^{-4} \mathrm{~cm}^{-2}$ in a non-uniform distribution. Wang et al. states that below this point the amount of divacancies doesn't represent a problem for radiation detectors application, since its amount isn't high enough to influence its application requirements [50].

Another approach to avoid such oxide formation as well as minimize the dislocation density of the crystal can be seen in the investigation of Taishi et al., where in addition to Argon atmosphere, they also used a layer of liquid $\mathrm{B}_{2} \mathrm{O}_{3}$ at the surface of the Germanium melt to entrap the oxides and to promote a reduction reaction of $\mathrm{GeO}_{2}$ with the free Boron at the $\mathrm{B}_{2} \mathrm{O}_{3} / \mathrm{Ge}$ melt interface. The result was a much lower level of dislocation density, which could also be related with the influence of oxides on the melt surface [56] [57].

Crucible material and design: Germanium will expand at rates of approximately $6 \%$ during its transition from melt to solid [58]. In the lack of proper crucible design to accommodate this expansion as well as the lack of considerations about the crucible material properties such as wettability, etc., the crucible will most likely break while solidification of Germanium. Kaiser et al. investigated the wettability of Germanium on different substrates and showed that nitrogen- and carbon-based substrates will lead to a higher wetting angle, while oxygen-based ones have lower wetting angle. Furthermore, for oxygen-based substrates, some reaction between Germanium and the substrate was identified by their experiments due to the detection of oxygen contamination in the Germanium melt [46].

Therefore, as the most optimum material either high purity graphite or, when a certain quality is needed, ultra-high purity quartz should be used. Both systems have some disadvantages too, for example graphite crucible can lead to boron and phosphor contamination, while quartz favors the formation of aluminumoxygen complexes (Aluminum as one of main impurities in Germanium beside Boron and Phosphor coming from raw material) due to the release of oxygen from the crucible or an oxygen-rich atmosphere at the melt interface.

\section{Conclusions}

According to DERA (Deutsche Rohstoffagentur/German Mineral Resources Agency) and USGS (United States Geological Survey), Germanium has a limited supply 
in the world, though its demand is rising fast, going from 160 ton in 2014 to up to forecasted 300 ton by 2030 and mostly being used in Semiconductor and Fiber Optics sector.

The current methodologies of Germanium production and refining haven't been changed in the last decades. Some isolated improvements in the methodologies were certainly made by the companies but the base of these main technologies, especially in the ultra-purification of Germanium by Zone melting, remains still the same.

The increase in demand and the upcoming rise in prices will most likely push the industry for alternatives, especially in the cost and time-consuming process of Germanium ultra-purification. A promising alternative investigated with the focus on Aluminum metal system based on a rotational cooling body [59] as crystallizer has showed a great potential to be a replacement technology for the recycling ultra-pure Germanium, drastically decreasing the process time and costs while achieving similar purification results. In this process the high-grade metallic scraps (Aluminum so far) can be melted in a crucible. The crystallizer is inserted into the melt and the crystallization starts. This process works based on the fractional crystallization too, where due to small temperature gradient between the cooled wall of the crystallizer and the adjacent melt, a growth front is formed and moves radially in direction of the crucible wall. The rotational mechanism promotes a homogeneous mixture of the melt and a stable boundary layer, which will assure an optimal segregation of the impurities [60]. In one batch treatment (approx. 1 h) with an initial purity of $3 \mathrm{~N}$, an end product with $5 \mathrm{~N}$ purity is guaranteed and can be even increased by repeating the batch numbers.

\section{Acknowledgements}

The Authors would like to appreciate the CNPQ-Brazilian National Council for Scientific and Technological Development for the financial support of the Brazilian scholarship holder and guest researcher D. Curtolo.

\section{References}

[1] Melcher, F. and Buchholz, P. (2012) Current and Future Germanium Availability from Primary Sources. Minor Metals Conference, Cologne, 24 April 2012, 5.

[2] Höll, R., Kling, M. and Schroll, E. (2007) Metallogenesis of Germanium-A Review. Ore Geology Reviews, 30, 145-180. https://doi.org/10.1016/j.oregeorev.2005.07.034

[3] Jorgenson, J.D. (2006) Germanium Recycling in the United States in 2000. United States Geological Survey, Reston, Virginia.

[4] Claeys, C. and Simoen, E. (2007) Germanium Based Technologies. Elsevier Science, Amsterdam.

[5] Bleiwas, D.I. (2010) Byproduct Mineral Commodities Used for the Production of Photovoltaic Cells. United States Geological Survey, Reston, Virginia.

[6] Guberman, D.E. (2017) Mineral Commodity Summaries. United States Geological Survey, Reston, Virginia.

[7] Moreno, A.M. and Sexton, S. (1998) Non-Ferrous Metal Works of the World. Metal 
Bulletin Books, London.

[8] Kelly, T. and Matos, G. (2017) U.S. Geological Survey, 2014, Germanium Statistics, Historical Statistics for Mineral and Material Commodities in the United States: U.S. Geological Survey Data Series 140. http://minerals.usgs.gov/minerals/pubs/historical-statistics

[9] Butterman, B.W.C. and Jorgenson, J.D. (2005) Germanium. U.S. Geological Survey, Reston.

[10] Melorose, J., Perroy, R. and Careas, S. (2014) Mineral Commodity Summaries. United States Geological Survey, Reston, Virginia.

[11] Moskalyk, R.R. (2004) Review of Germanium Processing Worldwide. Mining Engineering, 17, 393-402. https://doi.org/10.1016/j.mineng.2003.11.014

[12] Bracht, H. (2015) Self- and Dopant Diffusion in Silicon, Germanium, and Their Alloys. In: Kissinger, G. and Pizzini, S., Eds., Silicon, Germanium, and Their AlloysGrowth, Defects, Impurities and Nanocrystals, Taylor \& Francis Group, LLC.

[13] Singh, R., Oprysko, M. and Harame, D. (2004) Silicon Germanium: Technology, Modeling, and Design. Wiley-IEEE Press, Hoboken.

[14] Robertz, B., Verhelle, J. and Schurmans, M. (2015) The Primary and Secondary Production of Germanium: A Life-Cycle Assessment of Different Process Alternatives, JOM, 67, 412-424. https://doi.org/10.1007/s11837-014-1267-6

[15] Germanium, J.S.C. (2017) Zone Refining. http://eng.krasgermanium.com/processing/zone-refining

[16] 5N Plus (2017) Germanium Zone Refined Bar. http://www.5nplus.com/germanium.html

[17] Galaxy Compound Semiconductors (2017) Czochralski Crystal Growth. http://www.galaxywafer.com/galaxy/technology/crystal-growth/

[18] Wang, W.K., Peng, J.H. and Zhang, Z.B. (2011) Recovery Methods of Germanium. Advanced Materials Research, 295-297, 2267-2271.

https://doi.org/10.4028/www.scientific.net/AMR.295-297.2267

[19] Guggenbühl, W., Strutt, M.J.O. and Wunderlin, W. (1962) Halbleiterbauelemente. Birkhäuser Basel, Basel. https://doi.org/10.1007/978-3-0348-6854-9

[20] Weiser, K. (1958) Theoretical Calculation of Distribution Coefficients of Impurities in Germanium and Silicon, Heats of Solid Solution. Journal of Physics and Chemistry of Solids, 7, 118-126. https://doi.org/10.1016/0022-3697(58)90252-X

[21] Pfann, W.G. (1958) Zone Melting. Wiley, Hoboken.

[22] Cheung, N., Bertazzoli, R. and Garcia, A. (2008) Experimental Impurity Segregation and Numerical Analysis Based on Variable Solute Distribution Coefficients during Multi-Pass Zone Refining of Aluminum. Journal of Crystal Growth, 310, 12741280. https://doi.org/10.1016/j.jcrysgro.2008.01.007

[23] Burton, J.A., Prim, R.C. and Slichter, W.P. (1953) The Distribution of Solute in Crystals Grown from the Melt. Part II. Experimental. Journal of Chemical Physics, 21, 1987.

[24] Burton, J.A., Prim, R.C. and Slichter, W.P. (1953) The Distribution of Solute in Crystals Grown from the Melt. Part I: Theoretical. Journal of Chemical Physics, 21, 1987.

[25] Tiller, W., Jackson, K., Rutter, J. and Chalmers, B. (1953) The Redistribution of Solute Atoms during the Solidification of Metals. Acta Metallurgica, 1, 428-437. https://doi.org/10.1016/0001-6160(53)90126-6 
[26] Porter, D.A. and Easterling, K.E. (1992) Solidification. In: Porter, D.A., Ed., Phase Transformations in Metals and Alloys, Chapman \& Hall, London, New York, 1-56.

[27] Chatelain, M., Albaric, M., Pelletier, D. and Botton, V. (2015) Solute Segregation in Directional Solidification: Scaling Analysis of the Solute Boundary Layer Coupled with Transient Hydrodynamic Simulations. Journal of Crystal Growth, 430, 138147. https://doi.org/10.1016/j.jcrysgro.2015.08.013

[28] Wilson, L.O. (1978) On Interpreting a Quantity in the Burton, Prim and Slichter Equation as a Diffusion Boundary Layer Thickness. Journal of Crystal Growth, 44, 247-250. https://doi.org/10.1016/0022-0248(78)90199-9

[29] Nozawa, J., et al. (2013) Impurity Partitioning during Colloidal Crystallization. The Journal of Physical Chemistry B, 117, 5289-5295. https://doi.org/10.1021/jp309550y

[30] Hubbard, G.S., Haller, E.E. and Hansen, W.L. (1977) Zone Refining High-Purity Germanium. Nuclear Science Symposium, San Francisco, 19 October 1977, 1-2.

[31] Trumbore, F.A. (1960) Solid Solubilities of Impurity Elements in Germanium and Silicon. Bell System Technical Journal, 39, 205-303. https://doi.org/10.1002/j.1538-7305.1960.tb03928.x

[32] Statz, H. (1963) Maximum Solid Solubility and Distribution Coefficient of Impurities in Germanium and Silicon. Journal of Physics and Chemistry of Solids, 24, 699700. https://doi.org/10.1016/S0022-3697(63)80013-X

[33] Trumbore, F.A., Isenberg, C.R. and Porbansky, E.M. (1958) On the TemperatureDependence of the Distribution Coefficient: The Solid Solubilities of Tin in Silicon and Germanium. Journal of Physics and Chemistry of Solids, 9, 60-69. https://doi.org/10.1016/0022-3697(59)90091-5

[34] Haller, E.E., Hansen, W.L., Hubbard, G.S. and Goulding, F.S. (1976) Origin and Control of the Dominant Impurities in High-Purity Germanium. IEEE Transactions on Nuclear Science, 23, 81-87. https://doi.org/10.1109/TNS.1976.4328219

[35] Taishi, T., et al., (2010) Czochralski-Growth of Germanium Crystals Containing High Concentrations of Oxygen Impurities. Journal of Crystal Growth, 312, 27832787. https://doi.org/10.1016/j.jcrysgro.2010.05.045

[36] Spim, J.A., Bernadou, M.J.S. and Garcia, A. (2000) Numerical Modeling and Optimization of Zone Refining. Journal of Alloys and Compounds, 298, 299-305. https://doi.org/10.1016/S0925-8388(99)00655-6

[37] Rodway, G.H. and Hunt, J.D. (1989) Optimizing Zone Refining. Journal of Crystal Growth, 97, 680-688. https://doi.org/10.1016/0022-0248(89)90571-X

[38] Prasad, D.S., Munirathnam, N.R., Rao, J.V. and Prakash, T.L. (2006) Effect of Multi-Pass, Zone Length and Translation Rate on Impurity Segregation during Zone Refining of Tellurium. Materials Letters, 60, 1875-1879. https://doi.org/10.1016/j.matlet.2005.12.041

[39] Wang, S., Fang, H.S., Jin, Z.L., Zhao, C.J. and Zheng, L.L. (2014) Integrated Analysis and Design Optimization of Germanium Purification Process Using Zone-Refining Technique. Journal of Crystal Growth, 408, 42-48. https://doi.org/10.1016/j.jcrysgro.2014.09.019

[40] Yang, G., et al. (2014) Investigation of Influential Factors on the Purification of Zone-Refined Germanium Ingot. Crystal Research and Technology, 49, 269-275. https://doi.org/10.1002/crat.201300418

[41] Burger, A., Henderson, D.O., Morgan, S.H., Feng, J. and Silberman, E. (1990) Purification of Selenium by Zone Refining. Journal of Crystal Growth, 106, 34-37. https://doi.org/10.1016/0022-0248(90)90283-Q 
[42] Munirathnam, N.R., Prasad, D.S., Sudheer, C.H., Rao, J.V. and Prakash, T.L. (2005) Zone Refining of Cadmium and Related Characterization. Bulletin of Materials Science, 28, 209-212. https://doi.org/10.1007/BF02711249

[43] Mei, P.R., Moreira, S.P., Cardoso, E., Côrtes, A.D.S. and Marques, F.C. (2012) Purification of Metallurgical Silicon by Horizontal Zone Melting. Solar Energy Materials and Solar Cells, 98, 233-239. https://doi.org/10.1016/j.solmat.2011.11.014

[44] Roussopoulos, G.S. and Rubini, P.A. (2004) A Thermal Analysis of the Horizontal Zone Refining of Indium Antimonide. Journal of Crystal Growth, 271, 333-340. https://doi.org/10.1016/j.jcrysgro.2004.07.058

[45] Bhat, H.L. (2014) Introduction to Crystal Growth: Principles and Practice. CRC Press, Boca Raton. https://doi.org/10.1201/b17590

[46] Kaiser, N., Croell, A., Szofran, F.R., Cobb, S.D., Dold, P. and Benz, K.W. (2001) Wetting Angle and Surface Tension of Germanium Melts on Different Substrate Materials. Journal of Crystal Growth, 231, 448-457. https://doi.org/10.1016/S0022-0248(01)01480-4

[47] Hult, M., Belogurov, S., Caldwell, A., Janicsko, J., Kornoukhov, V. and Schönert, S. (2008) On the Underground Production of High Purity Germanium Detectors. Office for Official Publications of the European Communities, Luxembourg.

[48] Wang, G., et al. (2012) Development of Large Size High-Purity Germanium Crystal Growth. Journal of Crystal Growth, 352, 27-30. https://doi.org/10.1016/j.jcrysgro.2012.01.018

[49] Rudolph, P. and Nishinga, T. (2014) Handbook of Crystal Growth: Bulk Crystal Growth. Elsevier, 2, 389-397.

[50] Wang, G., et al. (2014) Dislocation Density Control in High-Purity Germanium Crystal Growth. Journal of Crystal Growth, 393, 54-58. https://doi.org/10.1016/j.jcrysgro.2013.11.075

[51] Roth, M., Azoulay, M., Gafni, G. and Mizrachi, M. (1990) Crystal-Melt Interface Shape of Czochralski-Grown Large Diameter Germanium Crystal. Journal of Crystal Growth, 99, 670-675. https://doi.org/10.1016/S0022-0248(08)80004-8

[52] Vojdani, S., Dabiri, A.E. and Ashoori, H. (1974) Diameter Control of Pulled Germanium Crystals by Means of Peltier Cooling. Journal of Crystal Growth, 24-25, 374-375. https://doi.org/10.1016/0022-0248(74)90338-8

[53] Friedrich, J., von Ammon, W. and Müller, G. (2014) Czochralski Growth of Silicon Crystals. In: Rudolph, P., Ed., Handbook of Crystal Growth: Bulk Crystal Growth, Elsevier Science, Amsterdam, 47-61.

[54] Depuydt, B. (2001) Encyclopedia of Materials: Science and Technology. Elsevier Science, Amsterdam.

[55] Yang, G., et al. (2012) Radial and Axial Impurity Distribution in High-Purity Germanium Crystals. Journal of Crystal Growth, 352, 43-46. https://doi.org/10.1016/j.jcrysgro.2011.12.042

[56] Taishi, T., Ohno, Y. and Yonenaga, I. (2009) Reduction of Grown-in Dislocation Density in Ge Czochralski-Grown from the $\mathrm{B}_{2} \mathrm{O}_{3}$-Partially-Covered Melt. Journal of Crystal Growth, 311, 4615-4618. https://doi.org/10.1016/j.jcrysgro.2009.09.001

[57] Taishi, T., Hashimoto, Y., Ise, H., Murao, Y., Ohsawa, T. and Yonenaga, I. (2012) Czochralski Growth Techniques of Germanium Crystals Grown from a Melt Covered Partially or Fully by Liquid $\mathrm{B}_{2} \mathrm{O}_{3}$. Journal of Crystal Growth, 360, 47-51. https://doi.org/10.1016/j.jcrysgro.2011.11.051

[58] Glazov, V.M. and Shchelikov, O.D. (2000) Volume Changes during Melting and 
Heating of Silicon and Germanium Melts. High Temperature, 38, 429-436. https://doi.org/10.1007/BF02756000

[59] Shingu, H., et al. (1984) Process for Producing High-Purity Aluminum. US Patent No. 4469512.

[60] Friedrich, S., Curtolo, D.C. and Friedrich, B. (2017) Effect of Process Parameter Variation on Purity during Rotary Fractional Crystallization of Aluminum. Open Journal of Metal, 7, 25-38. https://doi.org/10.4236/ojmetal.2017.72003 